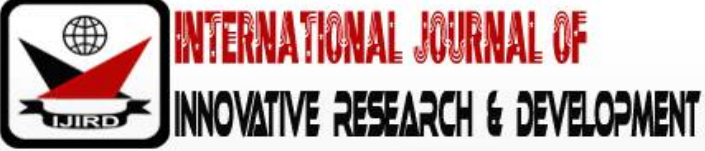

ISSN 2278 - 0211 (Online)

\section{Public Private Partnership (PPP) In Water and Sanitation (Watsan) Utility in Ga West Municipal Assembly of the Greater Accra Region, Ghana}

\author{
George Kwasi Agbenyegah \\ Senior Lecturer, School of Development Management, \\ Ghana Christian University College, Ghana
}

\begin{abstract}
:
WATSAN sector in Ghana since independence has implemented PPP reforms that aimed at enhancing the efficiency of the production and utilization. These reforms have culminated in the institutional re-alignment of key institutions in the sector. These PPP reforms in the history of Ghana were in two forms: The first form relates to assets ownership that remains with the public authority or government and it is known as Service and Management Contracts / Lease and Concessions .The second form where the assets are all or partially in private ownership (Kerf et al, 1998).
\end{abstract}

Keywords: WATSAN, Ghana, PPP, reforms and assets

\section{Introduction}

Water and Sanitation (WATSAN) sector has undergone a lot of PPP service provision (the role of the state vis-s-vis the non-state actor) with peculiar challenges all over the world in the last two decades. What differentiates the sector from other public sectors are as follows:

- Water is a basic human need for survival unlike other utilities such as electricity, airport and telecoms that have alternatives

- WATSAN services are provided under the condition of monopoly owing to its high cost investment that creates room for its political and PPP arrangement and involvement.

- Even though the cost of investment is high once made it cannot be reversed.

- Data on WATSAN services such as physical infrastructure and customer service are difficult to assess.

- WATSAN services and responsibilities are well suited for decentralized local management.

Water as economic good (must have value for money) verses'the right to water (arts.11 and 12 of the International ECOSAC Rights) that every human being has the right to clean water for consumption.

Owing to the above intrinsic peculiarities and challenges of WATSAN Sector, most water NGOs in Ghana viewed WATSAN sector to be the preserved for government but the 2White Paper on Water Services developed by South Africa, on one hand classifies water as an economic good and on the other handrecognises as human right to water, this therefore, callings for both State and Private Partnership.3Principle 4 of the Dublin Statement on Water and Sustainable Development also recognises Water as an economic good. However, stated that it is vital to recognise first the basic right of all human beings to have access to clean WATSAN at an affordable price. It is very vital to note herethat, no contradiction is made by recognizing human right to water and, at the same time as economic good that call for PPP investment. UN independent report in accordance with Council resolution 7/ 22 supports the above and did not make preference for any model of service provision but insists on guaranteeing of WATSAN human rights in all instances (Albuquerque, 2010).

\section{Background of the Study}

Ghana National Water Policy targeted all water users, water managers and practitioners, investors including PPP, decision- makers and policy makers within the central governmental and decentralized ( municipal / district assemblies) structures, non-governmental organisations and international agencies(Ministry of Water Resources, Works and Housing , 2007). The Policy gives mandate to Ghana Water Company to supply water to all inhabitants in the urban areas. Emergence of Service Providers and Public Utility Regulatory Commission (PURC)in 1997to regulate the water and electricity supply services in Ghana was also part of utility reform process. Decoupling of Community Water and Sanitation Agency (CWSA) and mandated by an Act of Parliament to focus mainly on rural and small town water supply in Ghana was

1 General Comment. No.15, The right to water (arts.11 and 12 of International Covenant on ECOSAG Rights),2002,E/ C.12/ 2002/ 11,para.18

2 Draft White Paper on Water Services, South Africa, October 2002, available at :htt:/ / www.info.gov.za

3 Dublin Statements on Water and Sustainable Development. International Conference on Water and the Environment, Dublin, January 1992 , Principle 4. 
also critical part of the reforms. Introduction of Public Private Partnership in Ghana: Decentralized Municipals (MAs) and District (Das) Urban, Small Towns and Rural Areas WATSAN Reforms was also initiated. These reforms or partnerships take the form of small scale businesses such as water tanker operators, community borehole operators and small town water operators in Atebubu, Nkoranza and others. This paved the way of private operator called Aqua Vitens Rand Limited who entered Service and Management Contract with the Government of Ghana in 2006. The consortium was to manage the utility on behalf of Ghana Water Company Limited (GWCL) but lasted briefly. After the exit of Aqua Vitens Rand Limited, the Government of Ghana decided to undertake a thorough restructuring of the water sector in Ghana with special emphasis on the urban sector in 2012.This restructuring exercise was based on an in-depth study of the sector including stakeholder consultation (which wasn't well exhausted); this also led to the formation of Ghana Urban Water Company (GUWCL) and its incorporation in 2012 as a subsidiary of the Ghana Water Company Limited (GWCL), with the Government of Ghana being the shareholder owning 100\% shares. Being a subsidiary of the GWCL, the GUWCL operated under the GWCL Board as a wholly state-owned enterprise. Currently, Ghana Netherlands Water Programme (GNWP) PPP Reforms was launchedamongst five selected MAs namely KEEA / Elmina, Ga South, Ga Central, Ga West and Cape Coast initially, registered Ghanaian Businesses, NGOs or Knowledge Institutions with their Dutch counterparts as Joint Venture in 2012. The project has been extended to over 100 hundred MAs throughout Ghana in 20014. It was implemented within the institutional framework of the water and environmental sanitations reforms in Ghana. This is to promote sustainability and ensure compliance with priority and policies. (GNWP, TOR, 2012-2016)

\section{Problem Statement}

Records available indicates hugebacklog investment needs in WATSAN infrastructure, for instance, ten countries in Central and Eastern Europe requires more than 120 billion euros, USA needs exceeded 325 billion US\$ and the rest of the world 1.5 trillion US\$ in the next 5 years ( World Bank, PPIAF PPI Data Base 2009). Whilst efforts are being made to meet the growing demands as a result of increase in population, the existing infrastructure is also deteriorating as well.The situation is not different in Ghana that relies heavily on external donor support for the water sector. Currently, Ghanacan only meet about half of her WATSAN demand. What worsens the situation is large losses in water delivery and cost recovery system.From the above, one realises that lack of investment in public WATSAN is not just limited to expansion or renewal of existing systems, but inability of the public funding for the management, operation and maintenance of the WATSAN systems is also critical.

\subsection{The Case of Ga West Municipal Assembly}

Ga West Municipal Assembly which ${ }^{4}$ lies within latitude 5048' North 5029' North and longitude 008' west and 0 030' West in Ghana and shares common boundaries with Ga East and Accra Metropolitan Assembly to the East, Akwapem South, Suhum Kraboa Coalter and West Akim to the North, Awutu Efutu Senya to the West and the Gulf of Guinea to the South with predominant ethnic groups of the ${ }^{5} \mathrm{Akan}$ (44.3\%), followed by the Ewe (25.7\%) and the Ga-Dangme (19, 1\%) . Figure 1: Location of Ga West Municipal Assembly is shown at annex_GWCL coverage of safe and clean water via piped system in the municipality is only $10 \%$ whilst the rest depends on streams, hand dug wells, dams and borehole constructed from CWSA, donors and others. Many of these boreholes (165 No) are saline (60\%) and this compelled the residents to result to fetching water from unwholesome sources. Owing to the insanitary conditions around dams as well as refuse dams close to the streams, the quality of water from such sources is unsafe for drinking. Out of the five municipal assemblies selected for GNWP, Ga West is least served with portable water.Ga West has the lowest ratio of people who rely on piped water for other purposes in the region. Therefore, urban centres, households and schools have limited access to drinking water to use for hygienic purposes (washing of hands after toilet) sanitation purposes (flushing of toilets and other purposes).This has led to the municipal assembly recording high incidence of water and sanitation borne diseases such as buruli ulcer, cholera, dysentery,amoebic, diarrhea and others. Currently the municipality is ranked as $2^{\text {nd }}$ most prevalent in buruli ulcer in Ghana. WASH services in schools are alarming. The demand for water in Ga West Municipal Assembly is shown below:

\begin{tabular}{|c|c|c|}
\hline Description & 2011 & 2016 \\
\hline Total Population & 121,674 & 134,998 \\
\hline Max. daily per capita consumption & $72 \mathrm{l} / \mathrm{cap} / \mathrm{d}$ & $72 \mathrm{l} / \mathrm{cap} /$ day \\
\hline Allow for non - domestic use & $10 \mathrm{l} / \mathrm{cap} /$ day & $10 \mathrm{l} / \mathrm{cap} /$ day \\
\hline Allow for non-revenue water & $41 \mathrm{l} / \mathrm{cap} /$ day & $411 / \mathrm{cap} /$ day \\
\hline Total maximum daily demand per capita & $123 \mathrm{l} / \mathrm{cap} /$ day & $123 \mathrm{l} / \mathrm{cap} /$ day \\
\hline Total daily water demand (m3/ day) & 14,970 & 16,605 \\
\hline
\end{tabular}

Table 1: The Demand for Water in Ga West Municipal Assembly

Sources: Ga West Watsan and medium Term Development Plan

The demand is constrained by Weija WTP only able to supply water to the municipality once a week. Nsawam WTP also supplies water to some parts of the eastern region at the same time serves the municipality with limited quantity. Other operators also have limited capacity and funds to expand water distribution in the municipality. The above 
challenges required innovative PPP solutions to increase coverage and service delivery which will take a very long time for GWCL and other operators to achieve due to high cost involved. Currently, the following PPP arrangements are in place:A number of NGOs have intervenedby providing package water treatment plants (Safe water Network) four of which are locatedin the municipality. However their capacity is very small. In addition, Nsawam water treatment plant that is operated by GWCL with current production capacity of 4,500m3 / day supplies water to the north-eastern part of the municipality. The MAalso collaborates with CWSA, NGOs and some of Communities to construct boreholes and sell the water on pay as you fetch basis. However, this is also limited in supply. Private entrepreneur, K.A Adu has partnered with GWCL in provision of potable pipe borne water at profit to some communities around Amasaman (Abehenease, Obeyeye, Fise and Ashaiman).Private tanker operators also sell water to the urban poor at a price which is over $100 \%$ cost of the GWCL.The foregoing facts show that PPP concept in the MA is not yet implemented on large scale, this led to implementation of GNWP to encourage investments, operations, assets and risks to be shared among the partners ( both grantor and operators) so as to bring about the following benefits :

- Access: this is to enable the communities and schools to have reliable WATSAN delivery.

- Financial Sustainability: cost recovery through the sale of WATSAN services.

- Ownership: systems locally owned and managed.

- Employment: generates jobs to the community members so that both partners and beneficiaries will earn a living thereby reducing poverty.

- Operation will be run by partners and the local community in order to cover future costs for repairs and maintenance.

\section{Research Objectives}

The objective of the research is to:

- Identify and discuss the politics of WATSAN and stakeholders, assumptions, risks and management.

- WASH project processes and implementation.

- ascertain support private sector brings to public support in PPP arrangement

- identify best practices in legal, financial and asset management

- Identify standards of human rights to WATSAN (transparent and democratic decision making, accessibility to the pro poor at quality and quantity at affordable price by ensuring regulatory capacity and enforcement through monitoring and evaluation) and,

- Identify and recommend ways PPP can be structured so as to ensure long term viability and sustainability.

\section{Relevance and Justification of the Study}

The findings of the study will be used to determine efficiency and effectiveness of the impact (including human rights) and sustainability of the business cases including cost benefit analysis, PPP arrangement, structure (role, risks, financing, contractual and asset management and ownership issues) and make recommendations

\section{Research Questions}

The research questions which are intended to be answered cut across effective design, development and implementation or management of PPP arrangements for WATSAN sector:

- Who are major stakeholders and their involvement in WATSAN utility reforms?

- How do we utilize the strength of the private sector to support that of the public sector?

- What PPP arrangements work and what does not work?

- What is the feasible size of operation?

- Are setting standards of human rights to WATSAN met?

- Do we have lessons to be learnt?

- What legal, financial and multi-stage reform process and framework needs to be available to ensure ongoing, wide spread support change?

- What packages will inform and motivates potential business partners?

\section{Conceptional Framew ork}

The concepts deal with legal and technical approaches, procedure used to procure PPP arrangements that I need to use in desk review and field studies. They will also guide me inmaking research field analysis and compilation of results. They are shown below:

Setting Standards refers to regulations such as WATSAN services and facilities such as sufficient quantity, quality, regular supply,safety, acceptability, accessibility and affordability set up to monitor performance that has to be complied in line with human rights obligations and responsibilities (Albuquerque, 2010).

Systems for Sustainable Asset Management focuses on how to develop systems that improve utility performance and lock good management practices in place. Also, develop systems for operations and maintenance, asset management, and nonrevenue water reduction.

\subsection{Structure of Implementation}

- Support Process-stakeholder cooperation structure andmechanism, communication management and capacity building procedures. 
- Main Process involves preparation, planning, procurement, operation and renewal.

- Regulatory Process involves proactive risk management, transparency, accountability, customer focus, power balanced partnership, result orientedness, shared incentives, water resource protection, poverty responsiveness and sound financing mechanism (PPP for Water supply and Sanitation, SDC,SECO \& Swiss-Re, 2005)

\section{Data Collection Approach}

The approach that will be used to achieve the above will be desk study of international and local cases of PPP options in at least three countries vis a vis legal and technical, economic and social policies that exist for investment in Ghana. These findings will guide what has been achieved in those countries and what did not go well. Tools such as ranking and scoring, water and sanitation ladder, pocket charts, task chart, bar chart, utility value analysis, morphologic al box, objective oriented project planning (OOPP), tables, maps, Venn diagram, simple statistic, mass curve method, moving mean, discharge per unit area and others will be used in the analysis. Field data collection techniques will include interviews, focus group discussions, questionnaires and direct observation of both sample key State and Non State Actors such as officials from Ministries, NGOs, Private Sector, customers and Programme Management Consultants. For point source of data collection will focus on population, housing, types of point of source, condition / use of facility, cost, time needed, user satisfaction, functional status, projects, contracts, contractor, funding, adequacy of the flow of water, taste of water, population, gender sensitive nature of the facility, sort of improvement needed, willingness to pay,potential improvement among others.

\section{Research Plan}

The research will be presented in three main parts:

- Chapter 2-3 presents background information on stakeholders' analysis and cooperation, capacity building initiatives, PPP arrangement and structure, bankable project, level of service, costing and funding. Measuring of PPP performance in the longer term is also critical over here.PPP institutions are also looked at and the staged approach to PPP development and implementation are clearly defined in various levels as an aspect of literature review.

- Chapter 4-5 dilates on factors that can influence the effective development and operations of WATSAN PPP including legal and performance issues, understanding and managing risks, public and private funding and best practices in procurement processes. The sustainability of the utility facility and services are also considered alongside major risks that are core to success of the project. Monitoring and evaluation, Operation and maintenance also examined. Funding and finance which are critical for choice of PPP are determined whether the option is a bankable project or not. General procurement issues and dealing with existing PPPs and Renegotiation of issues left are also considered.

- Chapter 6 presents review of the entire research and concluding it recommendations to improve utility service sector delivery and performance (Rijksuniversiteit Groningen 2009).Sustainability in terms of economic, human, environmental are considered not only in financial terms. All the limitations in contractual agreements are review and recommendations are made for improvement. Dealing with adjustment of the developers' risks and payments are made.

\section{References}

i. Albuquerque, Caterina De (2010) Report of the Independence Expert on the Issue of Human Rights Obligations Related to Access to Safe Drinking Water and Sanitation presented at UN human Rights 15 Session. Available at htt:/ / daces-dds-ny.un.org/ docUNDOC/ GEN/ G10/ 148/ 31/ PDF/ G1014831.pdf?OpenElement

ii. Draft White Paper on Water Services, South Africa, October 2002, available at: http:/ / www.info.gov.za

iii. Dublin Statements on Water and Sustainable Development. International Conference on Water and the Environment, Dublin, January 1992, Principle 4.

iv. Hodges, John T and Georgina Dellacha (2007).Unsolicited Infrastructure Proposals: How Some Countries Introduce Competition and Transparency. PPIAF Working Paper 1.Washington, D.C.: World Bank.

v. Jim. K. (2008) Water Profile of Ghana. Encyclopedia of Earth Topics. Available online at http:/ / www.eoearth.org/

vi. GA West Municipal Assembly Water and Sanitation Plan. (2011 - 2014).Under Ghana Shared Growth and Development Agenda (GSGDA). Available online at

vii. http:/ / ghanadistricts.org/ districts/ ?r=1\&=1\&sa=1140 and

viii. http:/ / www.ghadistricts.com/ districts/ ?r $=4 \&=79 \& s a=4067 \&$

ix. General Comment. No.15, The right to water (arts.11 and 12 of International Covenant on ECOSAG Rights),2002,E/C.12/ 2002/ 11,para.18

x. Ghana Netherlands Water Project, TOR, 2012-2016

xi. Kerf, Michael, David Gay, Timothy Irwin, Celine Levesque and Robert Taylor (1998).Concession for Infrastructure: A guide to their Design and Award. World Bank Technical Paper n.399. World Bank: Washington, D.C. Available online at http:/ / rru.worldbank.org/ Tooklists/ Documents/ Concessions/ cover.pdf.

xii. Ministry of Water Resources, Works and Housing (2007). Ghana National Water Policy, Government of Ghana, Ministry of Water Resources, Works and Housing. Government of Ghana.

xiii. Klein, Michael and Bita Hadjimichael (2003). The Private Sector in Development: Entrepreneurship, Regulation, and Competitive Disciplines. Washington, D.C.: World Bank

xiv. Raymond Wasky (2008, October). Meetings and Symposia. IEE Antenas and Propagation Magazine 
xv. Rijksuniversiteit Groningen (2009) Optimizing Project Finance Solutions in the Water Sector Suggestion for Enhanced Public Private Partnerships. Available online at http:/ /

xvi. PPP for Water supply and Sanitation (2005). SDC,SECO \& Swiss-Re.

xvii. Veronika Fuesta and Stefan A. Haffnerb (2005). PPP-Policies, Practices and Problems in

xviii. Ghana's Urban Water Supply. Centre for Development Research, University of Bonn,

xix. Walter-Flex Str.3, 53113, Bonn, Germany

xx. Water and Sanitation \& Hygiene Programme (2012-2016). Embassy of the Kingdom of the Netherlands, Accra, Dutch Ministry of Foreign Affairs Tender Documents Terms of Reference, Ex Ante Evaluation Feasibility Study and Baseline Survey.

\section{Annexure}

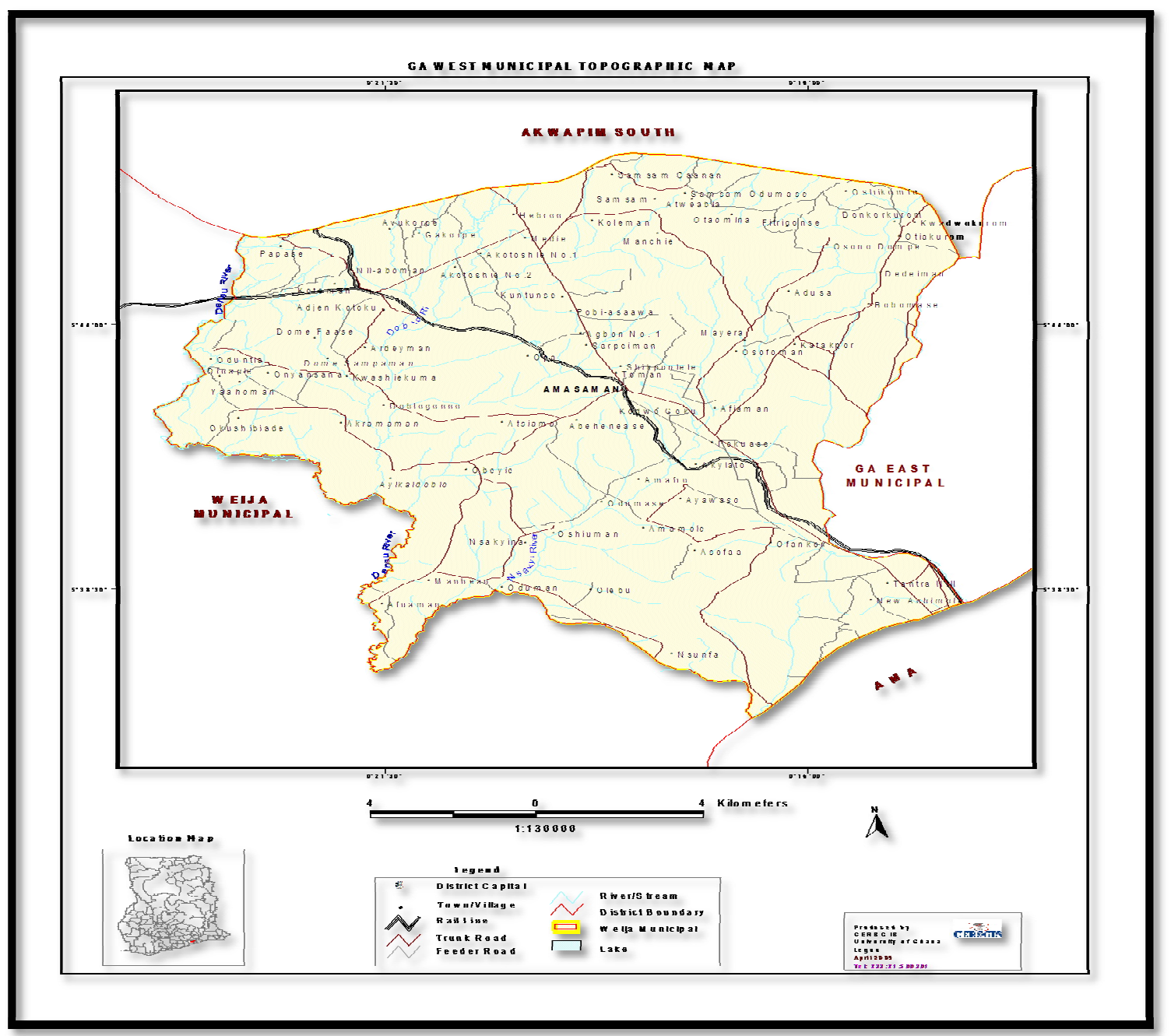

Figure 1: Location of Ga West Municipal Assembly

Source: Raymond Wasky (2008, October). Meetings and Symposia,

IEE Antenas and Propagation Magazine 